\title{
Global policy challenges for urban vector-borne disease risks
}

\author{
Alabaster $\mathrm{GP}^{1}$
}

\begin{abstract}
Affiliation
${ }^{1}$ Chief Waste Management \& Sanitation, Urban Basic Services Branch, United Nations Human Settlements Programme, Geneva Office, CH

*Correspondence: alabaster.unhabitat@unog.ch
\end{abstract}

Suggested citation: Alabaster GP. Global policy challenges for urban vector-borne disease risks. Can Comm Dis Rep 2016;42:203-4. https://doi.org/10.14745/ccdr.v42i10a05

\section{Background}

Current urbanization patterns are having significant impacts on the epidemiology of vector-borne diseases (VBDs), particularly in the low- and middle-income world. A better understanding of urban typologies and monitoring of vulnerable populations will enable improved environmental management and targeted interventions.

\section{Objective}

To explore global policy challenges and immediate and long-term approaches to address urban VBD risks.

\section{Narrative}

Poor urban communities are most vulnerable to VBDs. For example, the recent spread of Zika virus in low- and middle-income countries has been facilitated by urban crowding and poor housing in conjunction with a lack of running water, inadequate water storage, poor surface water drainage and waste management. The spike in Zika-related microcephaly cases concentrated in the poor and underdeveloped north-east of Brazil has been one of its most unfortunate outcomes.

UN-Habitat, as the agency for sustainable urban development seeks to influence the growth of cities through improved urban planning and provision of appropriate infrastructure. It also has the tools and experience to enhance the capacity of local governments and communities in emergency contexts to upgrade basic services to reduce transmission of VBDs, compliment other medical interventions and facilitate surveillance and mosquito (and other vector) control.

Previous experiences in mitigating epidemics show that community participation is critical. In particular, lessons can be drawn from decades of efforts to reduce the spread of the dengue virus. People are more likely to support control policies and adopt preventative measures when they are involved. Community outreach has also shown to have a positive impact on citizen cooperation and trust in authorities (1).

On a global level, the sustainable development agenda provides an opportunity to develop indicators and targets that show the importance of health as a precondition for sustainable development (2). Embedding health-related indicators in the post-2015 goals can help to raise awareness of the probable health gains from sustainable development policies, and the costs of not adopting these policies. For example, previously we did a poor job at increasing awareness of the health care costs of urban sprawl.

There are many reasons why urban sprawl is bad for health. One reason is that the low population densities mean that the per capita costs of service provision are extremely high (3), particularly for networked systems to deliver clean water and remove excreta and wastewater. Also, access to critical health-care facilities becomes increasingly difficult. Improving mobility is also important. The benefits of recent efforts to mitigate urban sprawl by increasing urban density along public transit lines and providing walking-friendly spaces in urban areas has made addressing urban sprawl more attractive to decision makers.

As part of the immediate response to urban VBD risks, heightened surveillance and mosquito control measures are critical. There is a need to understand more fully the pattern of the disease transmission in low-income areas of larger cities. This is frequently in the periurban areas. In most informal settlements the citizens have no fixed geographical location. In addition, their lifestyle is often transient. Giving low-income populations a physical address not only enables them to gain access to essential services but also provides disaggregated health data. To address the vulnerability of affected populations at the source, investments need to be made towards improving water storage, sanitation and drainage, garbage collection and housing. Zika is a good example in this respect. The aedes vector is exclusively a "container bred" mosquito. Covering water containers and collecting garbage, which allows water to accumulate, can greatly contribute to effective control.

\section{Conclusion}

As a part of a long-term control strategy, there is a need to address the underlying urban poverty and its conditions that give rise to epidemics such as Zika and develop indicators and targets that show the importance of health as a precondition for and an outcome of policies to promote sustainable urban development. Taking a closer look at urban planning, the provision of basic infrastructure and housing design, and increasing infrastructure 
investments will greatly reduce the current spread as well as future outbreaks of vector-borne diseases.

\section{Conflict of interest}

None.

\section{References}

1. Blas E on behalf of the United Nations Development Programme and Roll Back Malaria Partnership. [Internet] Multi-sectoral Action Framework for Malaria. [cited 14 September, 2016]. Available at: https://issuu.com/undp/ docs/multisectoral_action_frameowkr_for_.
2. Dora C, Haines A, Balbus J, Fletcher E, Adair- Rohani $\mathrm{H}$, Alabaster $\mathrm{G}$, et al. Indicators linking health and sustainability in the post-2015 development agenda. Lancet. 2015;385(9965):380-91.

3. Hortas-Rico M, Solé-Olé. Does Urban Sprawl Increase the Costs of Providing Local Public Services? Evidence from Spanish Municipalities. Urban Stud. 2010;(7):1513-40.
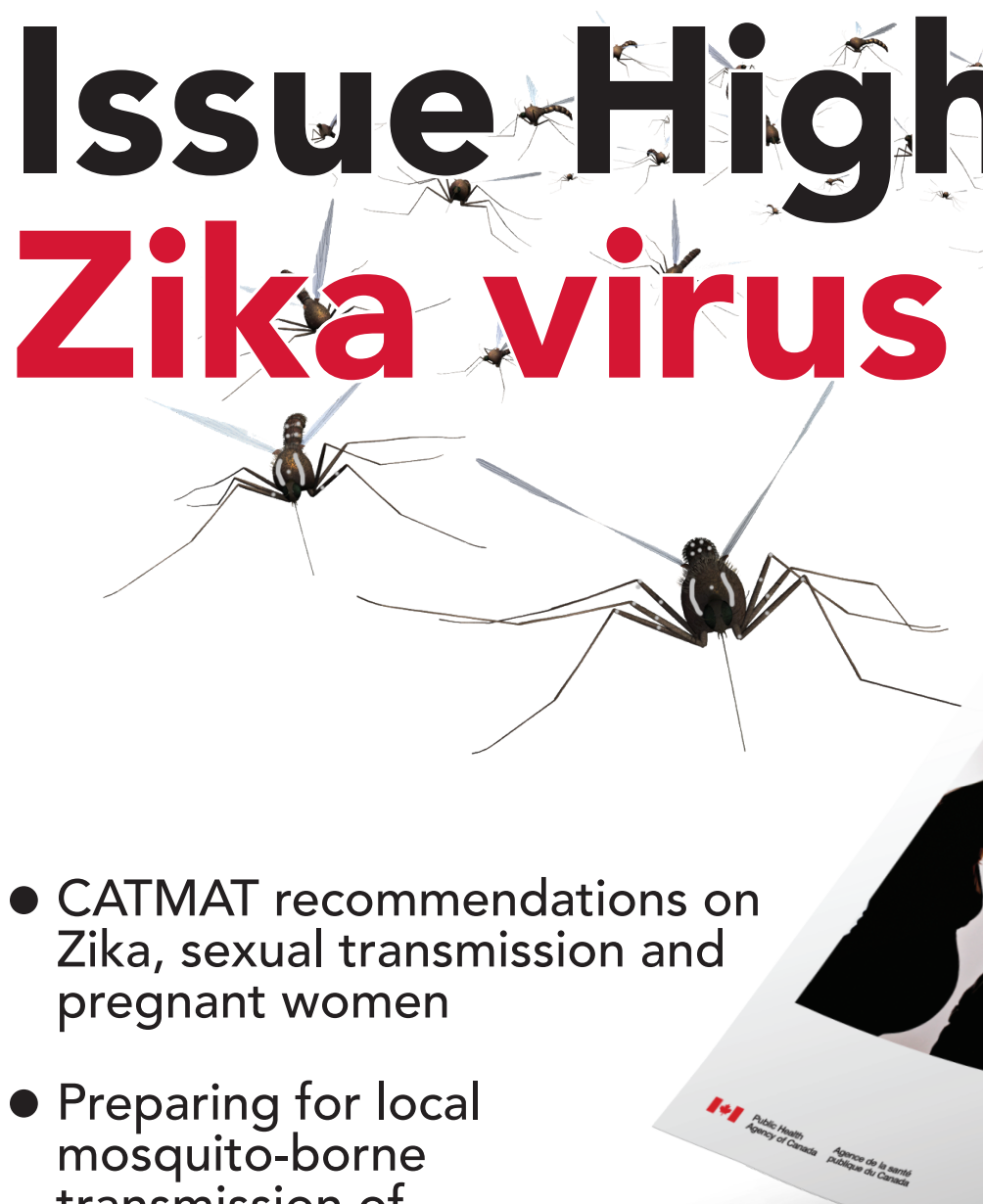

- CATMAT recommendations on Zika, sexual transmission and pregnant women

- Preparing for local mosquito-borne transmission of Zika virus in the United States

- Massive vaccination to arrest yellow fever outbreak in Angola
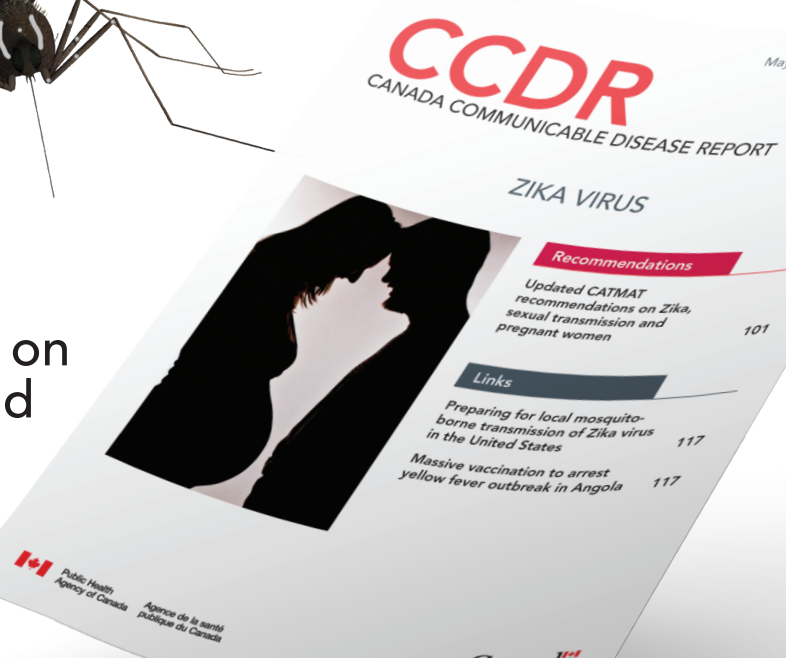

$x^{+}+$

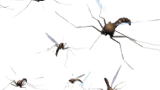

\section{ZKA VIRUS}

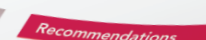

Uodoted CATMAT recomimendotions on
sexual transming

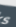

ks

作

in the United States

yellow wever vaccination to arrest

(utereak in Angola

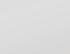

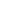

.

